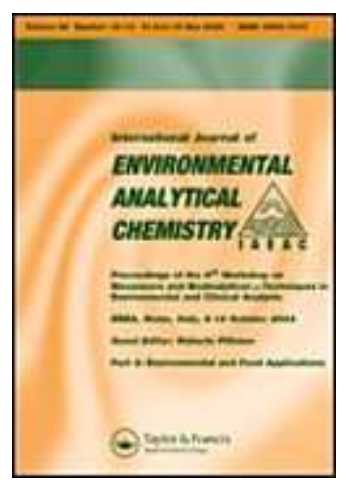

\title{
Improvement in levoglucosan quantification in atmospheric particulate matter by high performance anion-exchange chromatography coupled with pulsed amperometric detection
}

\begin{tabular}{|r|l|}
\hline Journal: & International Journal of Environmental Analytical Chemistry \\
\hline Manuscript ID: & GEAC-2009-0036 \\
\hline Manuscript Type: & Original Paper \\
\hline Date Submitted by the & 21 -Jan-2009 \\
\hline Complete List of Authors: & $\begin{array}{l}\text { Piazzalunga, Andrea; Department of Inorganic, Metallorganic and } \\
\text { Analytical Chemistry, University of Milan; Department of } \\
\text { Environmental Sciences, University of Milan - Bicocca } \\
\text { Fermo, Paola; Department of Inorganic, Metallorganic and } \\
\text { Analytical Chemistry, University of Milan } \\
\text { Vecchi, Roberta; Institute of General Applied Physics, University of } \\
\text { Milan } \\
\text { Valli, Gianluigi; Institute of General Applied Physics, University of } \\
\text { Milan } \\
\text { Bernardoni, Vera; Institute of General Applied Physics, University of } \\
\text { Milan } \\
\text { De Gregorio, Maria; Environmental Protection Agency of Lombardy } \\
\text { Region, Department of Milan }\end{array}$ \\
\hline Keywords: & $\begin{array}{l}\text { atmospheric aerosol, levoglucosan, HPAEC-PAD, anydrosugars, } \\
\text { biomass burning, wood combustion }\end{array}$ \\
\hline \hline
\end{tabular}

\section{s ScholaroNE" Manuscript Central}


Improvement in levoglucosan quantification in atmospheric particulate matter by high performance anion-exchange chromatography coupled with pulsed amperometric detection 


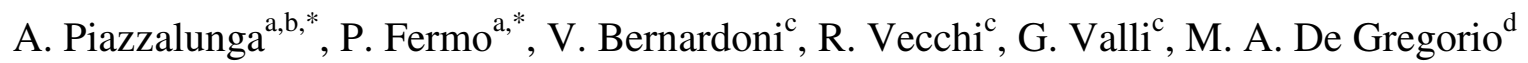

${ }^{a}$ Department of Inorganic, Metallorganic and Analytical Chemistry, University of Milan, Via Venezian 21, 20133 Milan, Italy

${ }^{\mathrm{b}}$ now: Department of Environmental Sciences, University of Milan - Bicocca, Piazza della Scienza 1, 20126 Milan, Italy

${ }^{\mathrm{c}}$ Institute of General Applied Physics, University of Milan ,Via Celoria 16, 20133 Milan, Italy

${ }^{\mathrm{d}}$ Environmental Protection Agency of Lombardy Region, Department of Milan, via Juvara 22, 20133 Milan, Italy

*Corresponding authors: andrea.piazzalunga@unimib.it 


\begin{abstract}
Levoglucosan, a tracer for the assessment of biomass burning contribution to atmospheric particulate matter (PM) concentrations, was determined by means of high-performance anionexchange chromatography (HPAEC) with pulsed amperometric detection (PAD). In this work we propose a variation in the instrumental set-up to improve the performance of the analytical technique. The comparison between this technique and the one commonly used (GC-MS) showed good agreement. Repeatability is $4.8 \% \mathrm{RSD}$, limits of detection for individual sugar are in the range $0.01-0.02 \mu \mathrm{g} \mathrm{mL}^{-1}$ in solution, corresponding to $3-4 \mathrm{ng} \mathrm{m}^{-3}$ for $24 \mathrm{~m}^{3}$ of air sampled. PM10 samples were characterized for levoglucosan and for organic and elemental carbon contents. The preliminary results here reported for some sites in the Lombardy region (Northern Italy) are, as far as we know, the first data available on the contribution of residential wood combustion in Italy. The levoglucosan concentrations observed in Lombardy vary in the range $173-973 \mathrm{ng} \mathrm{m}^{-3}$ and are lower in the cities and higher at rural sites.
\end{abstract}




\section{Keywords}

atmospheric aerosol, levoglucosan, HPAEC-PAD, anydrosugars, biomass burning 


\section{Introduction}

Many studies have recently focused on the determination of elements and compounds, which can be markers for a specific source for atmospheric particulate matter (PM). This is the case of some saccharides, such as levoglucosan (1,6-anydro- $\beta$ D-glucopyranose). This compound is an anhydrosugar, which is considered together with soluble potassium and oxalate, as a good signature of biomass/wood combustion in atmospheric particulate matter samples $[1,2]$. It is noteworthy that potassium can also be derived from soil and other sources such as meat cooking, waste incinerators and coal usage $[1,2]$, while oxalate can be formed in the atmosphere from hydrocarbons emitted by other primary sources $[1,2]$. Therefore, levoglucosan could be a more specific tracer for biomass/wood burning [1].

Wood smoke contains high concentrations of levoglucosan as levoglucosan itself is a degradation product and arises from the pyrolysis of cellulose. It is one of the most abundant organic components of smoke particles and is emitted during biomass burning processes together with compounds present in minor quantities such as terpenoids, resins, gums and biopolymers. Minor quantities of levoglucosan isomers, i. e. galactosan and mannosan, are emitted too. These two stereoisomers result from the pyrolysis of hemicellulose and are also specific markers for biomass burning. It is interesting to note that the mannosan to levoglucosan ratio allows the estimation of the proportion between hard- and softwood smoke in atmospheric PM [7].

In contrast to other molecular markers of biomass burning (i.e. diterpenoids, triterpenones, etc.) levoglucosan is emitted in large amounts, is sufficiently stable, is specific to cellulose-containing substance and meets all important criteria to serve as an ideal molecular marker of biomass burning $[1-11]$.

During the last years increasing efforts have been put into levoglucosan quantification. Recently, the analytical methods mainly employed for this marker quantification have been reviewed [1]. 
They can be divided into two main categories: gas chromatographic (GC) techniques and methods based on liquid chromatography (LC) analysis.

Up to now, GC/MS has been the most commonly applied technique for levoglucosan quantification $[8,13]$. Even if the whole procedure for GC-MS analysis is well established, the main drawback is due to the fact that it is a quite elaborate procedure, which includes extraction with organic solvents, evaporation and also a final step of derivatization, using trimethylsilyl esters, which represents the tricky point. Although GC/MS allows the determination of numerous species in a single analysis with a good resolution, it is time consuming and expensive because of the sample preparation step. For LC analyses different systems can be used: HPLC-HRMS [14], LC-ESI [15], HPLC-ACD [16], HPLC-MS-TOF [17], HPAEC-MS-ESI [18], and IEC-HPLC-PDA [19].

Another methodology recently suggested in the literature [9, 20, 21] makes use of High Performance Anion Exchange Chromatography (HPAEC) coupled with Pulsed Amperometric Detection (PAD). Ion-exchange chromatography is generally applied for the analysis of carbohydrates in samples of different nature [22] and HPAEC-PAD has been employed for the first time to detect monosaccharides in marine samples [23].

In the present study, levoglucosan has been quantified by both GC/MS and HPAEC coupled with PAD. HPAEC-PAD is sensitive, precise, and accurate $[4,20]$ and it does not require any complex extraction procedure followed by derivatization such as those needed by for GC-MS analyses. In particular, the sample preparation is very simple and levoglucosan can be directly analyzed in aqueous extracts, which are also used for the determination of PM ionic content.

In comparison with previous works $[4,20]$, the method here proposed for HPAEC-PAD analyses in PM samples has been optimized by means of a post column addition of concentrated sodium hydroxide, which allows a better sensitivity of the detector. Moreover, in order to use an isocratic pump the instrument was equipped with a system for the cleaning of the analytical column.

Particulate matter samples have been characterized for levoglucosan, the wood smoke tracer, and for organic and elemental carbon contents. OC (organic carbon) and EC (elemental carbon) were 
measured by Thermal Optical Transmittance method (TOT). If levoglucosan/OC ratio for wood emissions produced by wood stoves or fireplaces are known, levoglucosan measurements allow the estimation of the contribution of these sources to ambient particulate matter [10].

Nowadays very scarce data on the possible contribution of particles emitted by residential wood combustion in Italy are available while in the literature many data have been recently published on levoglucosan concentrations at different sites in Europe [24].

To achieve more information on this particulate matter source, which has not a negligible contribution to particulate matter concentrations [25] according to regional and national the emission inventories, PM samples collected at different locations in Lombardy region (Northern, Italy) have been chemically characterized for levoglucosan, OC and EC.

The sampling sites have been chosen according to the possible different contributions for wood combustion to particulate matter emissions. The preliminary results here reported are the first data available for the assessment of the contribution of residential wood combustion in Italy.

\section{Experimental}

\subsection{Chemical}

To prepare the standard solutions as well as to extract the samples $18.2 \mathrm{M} \Omega \mathrm{cm}^{-1}$ (Milli-Q, Millipore) water was used. Standards of levoglucosan (316555, CAS 498-07-7), mannosan, and galactosan were produced by Aldrich.

For the mobile phase, diluted sodium hydroxide solutions were prepared from $50 \%(\mathrm{w} / \mathrm{w}) \mathrm{NaOH}$ (Fluka 72064).

\subsection{Instrumentation}

The analyses were carried out by means of an ion chromatograph (Dionex ICS1000) equipped with an isocratic pump and a sample injection valve with a $100 \mu \mathrm{L}$ sample loop. The Chromeleon 
software was employed for the system control and data analysis. Different anydrosugars (levoglucosan, mannosan, and galactosan) were separated using a Carbopac PA-10 guard column (50mm x 4mm) and a Carbopac PA-10 anion-exchange analytical column (250mm x 4mm). As eluent $\mathrm{NaOH} 18 \mathrm{mM}$ was used. Each analysis took $25 \mathrm{~min}$ and was followed by a period of cleaning of the analytical column (see table 1); in order to achieve a better reproducibility the column was re-equilibrated for a period of 15 minutes before starting a new measurement. The column regeneration was performed at the end of each analysis in order to have constant retention times and to purge out every possible not eluted compound and finally to preserve the column from carbonate formation. The regeneration procedure consisted in the column washing using a more concentrated eluent ( $\mathrm{NaOH} 200 \mathrm{mM})$; in order to perform this task, the original two-ways eluent flow valve was changed in a three-ways one (see Figure 1 box a). The Chromeleon software was able to directly control the valve position. The two eluents tanks, connected with the eluent flow valve, were filled with $\mathrm{NaOH} 18 \mathrm{mM}$ and $200 \mathrm{mM}$, respectively. To prevent $\mathrm{CO}_{2}$ absorption, which could cause eluents carbonatation, both tanks were purged by a low He flow. The analysis program is schematically reported in Table 1 .

An amperometric detector (Dionex ED50) equipped with an Electrochemical Cell was installed in the system. The detector cell had a disposable gold electrode and a $\mathrm{pH}$ electrode as reference (both from Dionex) and was operated in Pulsed Amperometric Detection (PAD) mode.

In this work, detector sensitivity to different potential cycles was checked: two pulse patterns, defined as waveform A and waveform B and reported in Table 2 were tested. While waveform A uses a potential of $0.10 \mathrm{~V}$, waveform $\mathrm{B}$ uses $0.22 \mathrm{~V}$. The first one is generally suggested for carbohydrates analysis while the second one is for aminoacids determination.

Aiming at the enhancement of the analytes response (see the result and discussion section), the $\mathrm{pH}$ of the solution was suitably increased adding $\mathrm{NaOH} 500 \mathrm{mM}$ after the chromatographic column as shown in Figure 1 (box b). 


\subsection{Samples collection and preparation}

PM10 (particulate matter with aerodynamic diameter equivalent smaller than $10 \mu \mathrm{m}$ ) was sampled using low-volume sampler operating at $1 \mathrm{~m}^{3} \mathrm{~h}^{-1} .24$-hours samples were collected on quartz fibre filters, which were pre-fired at $700{ }^{\circ} \mathrm{C}$ for $1 \mathrm{~h}$.

PM10 was sampled at five sites in Lombardy (Northern Italy) during the period 21-27 February 2005. The sampling sites have different characteristics: Milan is the second largest town in Italy (about 1,200,000 inhabitants), Sondrio is an alpine town (about 21,000 inhabitants), Mantova is a medium-sized town (about 48,000 inhabitants) in the Southern part of the region, Bosco Fontana is a small rural village near Mantova, Cantù is a pre-alpine town (about 35,000 inhabitants) where wood furniture industrial production is the main activity.

PM mass concentration was determined using an analytical microbalance (sensitivity $1 \mu \mathrm{g}$ ) after 48 hours conditioning at about $30 \% \mathrm{RH}$. The uncertainty of gravimetric measurements was $\pm 2 \mu \mathrm{g} \mathrm{m}^{-3}$ and the limit of detection was $2 \mu \mathrm{g} \mathrm{m}^{-3}$.

The analytical procedure was optimized to analyze levoglucosan and its isomers in particulate matter samples using the same solutions already prepared for the ions quantification. This procedure is less time consuming and the sample can be stored for further analyses. In this work, a quartz fibre filter punch $\left(1.5 \mathrm{~cm}^{2}\right)$ was analyzed after extraction with $6 \mathrm{~mL} \mathrm{MQ-water} \mathrm{in} \mathrm{ultra-sonic} \mathrm{bath} \mathrm{[26].}$ Undissolved sample material and filter debris were removed from the sample solution by filtration ( $5 \mu \mathrm{m}$ filter, by Dionex) prior the injection.

\subsection{GC-MS analysis}

Levoglucosan concentrations were also determined for selected samples by means of GC-MS (Agilent Technologies 5973). Details about the sample preparation, the quantification procedure and the GC analytical conditions are reported in Pashynska et al. [8]. Metil- $\beta$-L arabinopyranoside was used as internal recovery standard for levoglucosan [27]. Briefly, a section of $1.5 \mathrm{~cm}^{2}$ of quartz filter was spiked with metil- $\beta$-L arabinopyranoside $(6 \mu \mathrm{g})$, and extracted for $30 \mathrm{~min}$ with $20 \mathrm{~mL}$ of 
dichloromethane-methanol $(80: 20, \mathrm{v} / \mathrm{v})$ under ultrasonic agitation. The extract volume was reduced with a rotary evaporator to about $1 \mathrm{~mL}$. The extract residue is trimethylsilylated with MSTFA $+1 \%$ TMCS and pyridine $(2: 1, \mathrm{v} / \mathrm{v})$ and the reaction was carried out for $60 \mathrm{~min}$ at $70^{\circ} \mathrm{C} .1 \mu \mathrm{L}$ of the derivatized solution was immediately analyzed by GC-MS.

\section{Result and discussion}

\subsection{Sample extraction and recovery}

The sample preparation procedure optimized for particulate matter ionic component analysis [26] is suitable also for anydrosugars analysis (see the experimental section). It consists in three subsequent extractions in an ultra-sonic bath for 20 min with the renewal of the solution in contact with filter at each step. To check the performance of the whole analytical procedure six filter portions with a known levoglucosan deposit were measured.

Test samples were prepared using 12 punches (area $1.5 \mathrm{~cm}^{2}$ ) taken from pre-fired quartz fibre filters, depositing on them $20 \mu \mathrm{L}$ of $250 \mathrm{ppm}$ levoglucosan solution $\left(5 \mu \mathrm{g}\right.$ sample $\left.\mathrm{e}^{-1}\right)$ and drying them during 24 hours. The recovery percentage was $98.7 \% \pm 7.0 \%$ for HPAEC-PAD and $101.7 \% \pm 5.1 \%$ per GC-MS.

Opposite to the sample preparation typical of GC-MS analysis, the HPAEC-PAD analytical approach does not need extraction with organic solvents, reductions in the solvent volume and derivatization. Moreover, the simpler extraction procedure avoids the internal standard use for recovery calculation making the method also less expensive than GC-MS.

\subsection{Response increase with $\mathrm{pH}$}

The instrumental response factor $\left(\mathrm{C} \mathrm{min}^{-1}\right)$ was calculated as the ratio between the peak area (C.min) and the quantity of the injected analyte $(\mathrm{g})$. It is worth noting that in order to achieve a good separation of the signals peaks, the eluent concentration should not be too high (i.e. high $\mathrm{pH}$ values). At the same time it is well known that the detector sensitivity for carbohydrates is lower at 
lower $\mathrm{pH}$ [9] while an improvement would be observed increasing $\mathrm{NaOH}$ concentration. In particular, for the separation and quantification of the less retained analytes (such as levoglucosan) the need of high sensitivity can compete with technique selectivity.

To overcome these problems, we introduced an improvement consisting in the post- column addition of the eluent at higher concentration $(\mathrm{NaOH} 500 \mathrm{mM})$, which produced an increase in the $\mathrm{pH}$ of the solution and a consequent enhancement of the instrumental response. In particular, varying the pressure in the tank with the post column eluent we were able to add different quantities of $\mathrm{NaOH} 500 \mathrm{mM}$ in the eluent flow by means of a $\mathrm{T}$ join (see Figure 1 box b). Changing the pressure in the tank, we varied the $\mathrm{pH}$ of the solution measured by the detector using the reference electrode. The trend of the response factor as a function of $\mathrm{pH}$ is reported in Figure 2.

The highest sensitivity was observed at $\mathrm{pH}=12.8$, a value obtained adding to the eluent coming from the column a quantity of $0.1 \mathrm{~mL} \mathrm{~min}^{-1}$ of the $\mathrm{NaOH}(500 \mathrm{mM})$ solution which, in our experimental set-up, corresponded to apply a counter pressure of 1.6 PSI.

\subsection{Response at different waveform and chromatographic separation}

It is important to note that we obtained a good separation in the anydrosugars by means of an isocratic pump, while in other literature works $[9,20]$ a gradient system was used. In fact, we cleaned the column from the possible presence of not eluted species introducing a more concentrated $\mathrm{NaOH}$ solution by means of a three ways valve (see the instrumentation section). The instrumental performances were checked analyzing standard solutions at different concentrations containing the three anydrosugars (levoglucosan, mannosan, and galactosan) and glucose. We decided to add glucose to the standard solution to check the correct performance of the instrument comparing the experimental response with the expected one according to manufacturer's specifications [28]. Since glucose is more retained than anydrosugars, it allows checking the retention times stability. Furthermore, glucose is interesting since it has not negligible 
concentrations in summer PM samples having fungi, lichens, soils and plants as possible sources $[8]$.

In Table 3 the analytes response variation with the two different applied potentials is shown.

The comparison shows a significant increase in the instrumental response for the three anydrosugars using waveform B. Consequently, waveform B was chosen for the analyses.

The comparison between the chromatograms of the standard solution registered during the two different potential cycles is reported in Figure 3. It is noteworthy that waveform B is suggested by the constructor for amino-acids analyses, as they are not detected if waveform A is applied. However we chose to use waveform B for anydrosugars measurements as they show a better response with waveform B and amino-acids cannot represent an analytical interference since, as far as we know, up to now they have not been detected in atmospheric particulate matter. Moreover, in the analytical conditions described above, no amino-acid can elute because the analysis of these compounds need much more concentrated eluents [29].

A set of real PM samples $(n=18)$ selected among those sampled in Lombardy (see the experimental section) have been analyzed using the two different potential cycles. The comparison between the levoglucosan analytical signals obtained with waveforms A and B is reported in Figure 4. The very good correlation $\left(\mathrm{R}^{2}=1\right)$ highlights the interferences absence, while the slope (1.95) shows the sensitivity increase when using waveform B.

The technique is highly linear in the 10 ppb-2 ppm concentration range and the calibration parameters obtained for the three anydrosugars are reported in Table 4.

\subsection{Analytical interferences}

In a recent paper by Caseiro et al. [9] the presence of arabitol in PM samples and its interference in levoglucosan quantification are shown. Arabitol has been recently proposed as tracer for the quantification of the contribution of fungal spores to PM [10]. During wintertime, arabitol contribution can be considered negligible while levoglucosan concentrations are higher because of 
wood smoke emissions; on the contrary, during summer when biological source emissions are more effective, arabitol must be taken into account.

These authors observed the partial overlapping of levoglucosan and arabitol peaks using a CarboPac PA1 analytical column and $\mathrm{NaOH} 0.5 \mathrm{mM}$ as eluent. In this way, the chromatographic peaks deconvolution and the signals resolution were possible allowing the quantification of both levoglucosan and arabitol.

With the analytical procedure proposed in this study, the two species completely overlap and so the interference cannot be resolved by peaks deconvolution. So an alternative method has been proposed to assess arabitol presence in real PM10 samples consisting in the hydrolyzation of levoglucosan to glucose [16] which has a different retention time allowing to put in evidence arabitol signal.

For this purpose a mixture of levoglucosan and arabitol has been treated with $0.1 \mathrm{M} \mathrm{HCl}$ at $85{ }^{\circ} \mathrm{C}$ for $28 \mathrm{~h}$ in order to completely hydrolyze levoglucosan to glucose. Two analyses have been required for each sample in order to evaluate levoglucosan and arabitol contributions: the first one without hydrolysis and the second one after the hydrolysis. The peak present after hydrolysis at the same retention time of levoglucosan is due to arabitol.

Literature data on arabitol and levoglucosan atmospheric concentrations are reported in Table 5. During wintertime, arabitol atmospheric concentrations are much lower (about a factor 10-20) than levoglucosan ones so that arabitol intereference can be neglected in winter samples (as done in our case).

As concerns summertime samples, the arabitol presence could be verified submitting filter portions to the hydrolysis procedure; work on this topic is still in progress.

\subsection{Repeatability and limit of detection}

To test instrumental repeatability, three standards of levoglucosan solutions (in the 0.1-2 ppm range) were analyzed five times with HPAEC-PAD and nine times with GC-MS. The repeatability 
of the HPAEC-PAD, defined as the percetege relative standard deviation, was $4.8 \%$ while for GCMS was $5.5 \%$.

The limits of detection (LOD) are assessed as the analyte concentration giving a signal equal to the blank signal, $\mathrm{y}_{\mathrm{B}}$, plus three standard deviations of the blank, $\mathrm{s}_{\mathrm{B}}[30]$.

In Table 6, LOD for levoglucosan, mannosan and galactosan are reported. They were obtained applying waveform $\mathrm{B}$ to the detector and setting the eluent at $\mathrm{pH}=12.8$.

When we refer to 24-hours particulate matter samples, obtained by low volume samplers $\left(1 \mathrm{~m}^{3} \mathrm{~h}^{-1}\right)$ the LODs are reported as $\mathrm{ng} \mathrm{m}^{-3}$ (see Table 6).

These values are similar to those obtained by Caseiro et al. [9], but we used a smaller filter portion $\left(1.5 \mathrm{~cm}^{2}\right.$ vs. $\left.4.5 \mathrm{~cm}^{2}\right)$. Thus, our methodology is very suitable when different analyses have to be carried out on the same filter.

\subsection{Comparison between HPAEC-PAD and GC-MS}

Anydrosugar mass concentrations obtained by HPAEC-PAD and GC-MS techniques in some wintertime particulate matter samples were compared. It is worth noting that the two methods differ significantly in separation and detection principles, and they use different sample preparation procedures [8]. Nevertheless, a good agreement in levoglucosan concentrations has been achieved as shown in Figure $5\left(\mathrm{R}^{2}=0.97\right)$.

The good agreement between the two techniques suggests that arabitol, if present in real wintertime samples, does not significantly affect measurements.

\section{Application to PM10 samples}

In PM10 samples, organic carbon (OC) and elemental carbon (EC) were also measured. The analyses were carried out by means of a Thermal-Optical Transmittance (TOT) analyzer [31, 32]. PM mass, carbonaceous fractions and levoglucosan concentrations are summarized in Table 7. The values registered in Lombardy are similar to those found at other sites in Europe [8]. 
The highest levoglucosan concentrations were registered in Sondrio and Cantù. These results are in agreement with information given by a survey carried out by the regional administration (Fondazione Lombardia per l'ambiente, PARFIL project), which identifies Sondrio as the city with the highest per capita wood use for domestic heating in Lombardy. Moreover, the high levoglucosan concentrations measured at Cantù are ascribed to the industrial activities related to wood furniture production. The strong impact of wood combustion in these sites is also pointed out by levoglucosan/OC ratio, which is higher in these two sites than at the other monitored sites.

Relatively low levoglucosan concentrations were registered in Bosco Fontana and the levoglucosan/OC ratio was quite similar to the one registered in Milan or Mantova, suggesting that Bosco Fontana was not strongly affected by wood burning. In Mantova, levoglucosan is higher than in Bosco Fontana, the small village nearby, indicating that residential wood combustion is larger in the urban area, where stoves and fireplaces are more abundant. Moreover, levoglucosan data in Mantova show a stronger variability than in the rural village, where less modulated levels suggest the presence of a background concentration.

In Milan, levoglucosan concentration and the levoglucosan/OC ratio are lower than in other sites, highlighting the importance of other sources (i.e. traffic or industries) in the urban area.

The preliminary data here presented give the first estimation of levoglucosan contribution to OC in Lombardy and also in Italy. In order to assess the impact of wood smoke on PM emissions, a more detailed and extensive study is in progress. In particular, the quantification of biomass burning as source will be achieved taking into account the chemical profiles from wood smoke samples derived by the combustion of different kinds of wood burnt in stoves or in fireplaces.

\section{Conclusions}

HPAEC-PAD has been identified as a suitable method for anydrosugar determination in atmospheric particulate matter. In fact: (i) this technique is highly sensitive if compared to 
atmospheric anydrosugar concentration $\left(\mathrm{LOD}=2 \mathrm{ng} \mathrm{m}^{-3}\right)$; (ii) if compared to the more widespread used technique, i. e. GC/MS, HPAEC-PAD requires an easier sample preparation, since it uses the same aqueous extracts already prepared for ion chromatography; (iii) this analysis is short-lasting, cheap and it requires simpler instrumentation.

It is worth noting that in this work an instrument provided with an isocratic pump has been successfully used for anydrosugar determination thanks to the column regeneration after each analysis with a simple modification of the instrumental set-up.

The increase of the eluent $\mathrm{pH}$ adding $\mathrm{NaOH}(500 \mathrm{mM})$ after chromatographic separation brings to a significant improvement in technique sensitivity. The use of a potential $(+0.22 \mathrm{~V})$ higher than the one commonly applied $(+0.10 \mathrm{~V})$ significantly improved the analytical signal intensity. Analytical performances obtained in this work allow using a small portion of filter (about 1/7 of a low volume sample). The analysis on real samples shows that atmospheric concentrations are much higher than LOD. This new system is well suited to handling large numbers of aerosol particulate matter samples.

Preliminary results obtained examining samples from different sites in Lombardy region, highlight that alpine cities (such as Sondrio), during wintertime are more influenced by wood smoke than the rest of the region. High levoglucosan concentrations measured at all sites point out that wood burning has to be considered one of the main primary PM sources.

\section{References}

[1] B.R.T. Simoneit, Environ. Sci. \& Pollut. Res. 6159 (1999).

[2] F.K. Duan, X.D. Liu, T. Yu, H. Cachier, Atmos. Environ. 381275 (2004).

[3] A.E. Sheffield, G.E. Gordon, L.A. Currie, G.E. Riederer, Atmos. Environ. 281371 (1994).

[4] L.M. Hildemann, G. R. Markowski, G.R. Cass, Environ. Sci. Technol. 25744 (1991).

[5] A.H. Falkovich, E.R. Graber, G. Schkolnik, Y. Rudich, W. Maenhaut, P. Artaxo, Atmos. Chem. Phys. 5781 (2005).

[6] R.S. Raman, P.K. Hopke, Intern. J. Environ. Anal. Chem. 86767 (2006).

[7] C. Schmidl, L.L. Marr, A. Caseiro, P. Kotianova, A. Berner, H. Bauer, A. Kasper-Giebl, H. Puxbaum, Atmos. Environ. 42126 (2008). 
[8] V. Pashynska, R. Vermeylen, G. Vas, W. Maenhaut, M. Claeys, J. Mass Spectrom. 37 1249 (2002).

[9] G. Schkolnik, Y. Rudich, Anal. Bioanal. Chem. 38526 (2006).

[10] C.A Gorin, J.L. Collett, P Herckes P, J. Air Waste Manage. Assoc. 561584 (2006).

[11] C. Dye, K.E. Yttri, Anal. Chem., 771853 (2005).

[12] E.C.H. Wan, J.Z. Yu, J. Chroma. A. 1107175 (2006).

[13] R.W. Dixon, G. Baltzell, J. Chroma. A. 1109214 (2006).

[14] K.E. Yttri, C. Dye, G. Kiss, Atmos. Chem. Phys. 74267 (2007).

[15] C. Bruggink, R. Maurer, H. Herrmann, S. Cavalli, F. Hoefler, J. Chroma. 1085104 (2005).

[16] A.H. Falkovich, Y. Rudich, W. Maenhaut, P. Artaxo, Environ. Sci. Technol. 392744 (2005).

[17] G. Engling, C. M. Carrico, S. M. Kreldenweis, J. L. Collett, Jeffrey L., D E. Day, W. C. Malm, E. Lincoln, W. M. Hao, Y. Iinuma, H. Herrmann, Atmos. Environ. 40 S299 (2006).

[18] S. Gao, D.A. Hegg, P.V. Hobbs, T.W. Kirchstetter, B.I. Magi, M. Sadilek, J. Geophys. Res-Atmos. 1088491 (2003).

[19] P. Kerherve, R. Buscail, F. Gadel, L. Serve, Org. Geochem. 33421 (2002).

[20] Y.S. Ding, S.F. Mou, Chinese J. Anal. Chem. 33557 (2005).

[21] H. Puxbaum, A. Caseiro, A. Sanchez-Ochoa, A. Kasper-Giebl, M. Claeys, A. Gelencser, M. Legrand, S. Preunkert, C. Pio, J. Geophys. Res-Atmos. 112 D23S05 (2005).

[22] ARPA Lombardia - Regione Lombardia. INEMAR, Inventario emissioni in atmosfera. in Lombardia nel 2005 - dati finali settembre 2007 (unpublished).

[23] P. Fermo, A. Piazzalunga, R. Vecchi, G. Valli, Chemical Engineering Transaction 10203 (2006).

[24] A.C. Ion, R. Vermeylen, I. Kourtchev, J. Cafmeyer, X. Chi, A. Gelencser, W. Maenhaut, M. Claeys, Atmos. Chem. Phys. 51805 (2005).

[25] Document No. 031481: product manual for the Aminopac PA10 analytical column, Aminopac PA10 guard column and AAA-direct, dionex analyzer, Dionex, (2006).

[26] (Dionex, product manual, Document No. 031481-12, 2006).

[27] J.N. Miller and J.C. Miller, Statistics and Chemometrics for Analytical Chemistry (Prentice Hall Publishers, Harlow 2005).

[28] P. Fermo, A. Piazzalunga, R. Vecchi, G. Valli, Chemical Engineering Transaction 1083 (2006).

[29] M.E. Birch, R.A. Cary, Aerosol Sci. Tech. 25221 (1996)

\section{Acknowledgements}

This work was partly founded by Regione Lombardia in the frame of the ParFiL project.

The authors are grateful to Prof. M. Clayes for having provided mannosan and galactosan standards and to C. Reschiotto for his valuable suggestions.

We would like to acknowledge F. Abballe, G. Ferracin, and L. Casagrande from Dionex (Italia) for their contribution to this research and ARPA Lombardia for PM10 samplings. 
Table

\begin{tabular}{lllll}
\hline Time & Eluent flow valve & Eluent & Acquisition & \\
\hline 0 & OFF & $\mathrm{NaOH}-18 \mathrm{mM}$ & OFF & Re-equilibration \\
15 & OFF & $\mathrm{NaOH}-18 \mathrm{mM}$ & $\mathrm{ON}$ & Injection \\
40 & ON & $\mathrm{NaOH}-200 \mathrm{mM}$ & OFF & Regeneration \\
50 & & & & End \\
\hline
\end{tabular}

Table 1: Eluent program and set-up of flow valve 


\begin{tabular}{lll}
\hline \multicolumn{1}{l}{ Time $(\mathrm{s})$} & Potential $(\mathrm{V})$ & Function \\
\hline Waveform A (Dionex Tech Note 21) & \\
\hdashline $0-0.2$ & +0.10 & Delay \\
$0.2-0.4$ & +0.10 & Integration \\
$0.41-0.43$ & -2.00 & Cleaning \\
$0.43-0.44$ & +0.60 & Conditioning \\
$0.44-0.50$ & -0.10 & Conditioning \\
& & \\
\hline Waveform B & & \\
$0-0.04$ & -0.20 & Conditioning \\
$0.05-0.21$ & +0.00 & Delay \\
$0.21-0.22$ & +0.00 & Integration Begin \\
$0.22-0.46$ & +0.22 & \\
$0.46-0.56$ & +0.00 & Integration End \\
$0.57-0.58$ & -2.00 & Cleaning \\
$0.58-0.59$ & +0.60 & Conditioning \\
$0.59-0.60$ & -0.20 & Conditioning \\
\hline
\end{tabular}

Table 2: Amperometric detector pulse patterns for sugars 


\begin{tabular}{llll}
\hline & levoglucosan & mannosan & galactosan \\
\hline waveform A & 0.10 & 0.11 & 0.11 \\
waveform B & 0.16 & 0.19 & 0.18 \\
\hline
\end{tabular}

Table 3: Response factor $\left(\mathrm{C} \mathrm{min}^{-1}\right)$ 


\begin{tabular}{llll}
\hline & levoglucosan & mannosan & galactosan \\
\hline & waveform A & & \\
\hline Slope & 9.38 & 10.84 & 11.00 \\
Slope standard error & 0.11 & 0.02 & 0.05 \\
R $^{2}$ & 1.00 & 1.00 & 1.00 \\
number of standards & 8 & 8 & 8 \\
& & & \\
& waveform B & \\
\hline Slope & 15.93 & 18.77 & 18.01 \\
Slope standard error & 0.01 & 0.00 & 0.01 \\
R 2 & 1.00 & 1.00 & 1.00 \\
number of standards & 8 & 8 & 8
\end{tabular}

Table 4: Analytical performance for three anydrosugars with two different amperometric patterns (x axis: concentration ( $\mu \mathrm{g} \mathrm{mL}-1)$, y axis: analytical signal ( $\mathrm{nC} * \min )$ ) 


\begin{tabular}{|c|c|c|c|c|c|c|}
\hline site & typology & 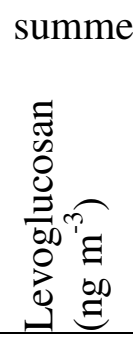 & 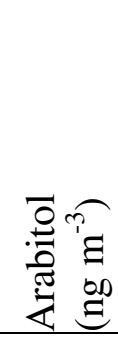 & 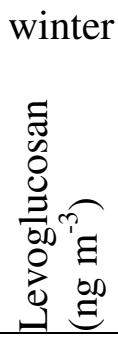 & 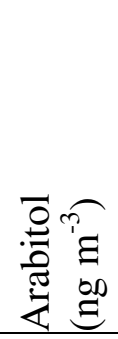 & Ref. \\
\hline $\begin{array}{l}\text { Ghent } \\
\text { (Belgium) }\end{array}$ & urban & 19.1 & 105 & 420 & 26 & [8] \\
\hline $\begin{array}{l}\text { Oslo } \\
\text { (Norway) }\end{array}$ & $\begin{array}{l}\text { urban } \\
\text { background }\end{array}$ & & & $193 *$ & $5.3^{*}$ & [17] \\
\hline $\begin{array}{l}\text { Elverum } \\
\text { (Norway) }\end{array}$ & suburban & 47 & 20 & 605 & 5.3 & [17] \\
\hline $\begin{array}{l}\text { Birkenes } \\
\text { (Norway) }\end{array}$ & background & $7.8^{* *}$ & $6.0 * *$ & & & [17] \\
\hline
\end{tabular}

* autumn mean $* *$ annual mean

Table 5: Levoglucosan and arabitol concentrations in aerosol samples 


\begin{tabular}{llll} 
& Levoglucosan & Mannosan & Galactosan \\
\hline LOD $\left(\mu \mathrm{g} \mathrm{mL}^{-1}\right)$ & 0.002 & 0.001 & 0.001 \\
LOD $\left(\mu \mathrm{g} \mathrm{m}^{-3}\right)^{\mathrm{a}}$ & 0.004 & 0.003 & 0.003
\end{tabular}

${ }^{\mathrm{a}}$ sampling flowrate $=1 \mathrm{~m}^{3} \mathrm{~h}^{-1}$ sampling time $=24 \mathrm{~h}$

Table 6: Levoglucosan detection limit 


\begin{tabular}{|c|c|c|c|c|c|c|}
\hline & & Sondrio & Cantù & Milano & Mantova & Bosco Fontana \\
\hline \multirow[t]{3}{*}{$\mathrm{PM}\left(\mu \mathrm{g} \mathrm{m}^{-3}\right)$} & mean & 47.4 & 64.5 & 72.6 & 100.2 & 85.7 \\
\hline & $\max$ & 58.2 & 80.7 & 94.7 & 130.5 & 112.4 \\
\hline & $\min$ & 34.8 & 39.3 & 25.7 & 39.3 & 36.3 \\
\hline \multirow[t]{3}{*}{$\mathrm{OC}\left(\mu \mathrm{g} \mathrm{m}^{-3}\right)$} & mean & 10.6 & 13.9 & 12.0 & 14.3 & 12.1 \\
\hline & $\max$ & 12.9 & 16.2 & 19.3 & 19.8 & 16.0 \\
\hline & $\min$ & 9.4 & 8.8 & 5.2 & 7.3 & 6.7 \\
\hline \multirow[t]{3}{*}{$\mathrm{EC}\left(\mu \mathrm{g} \mathrm{m}^{-3}\right)$} & mean & 3.8 & 2.3 & 2.7 & 2.8 & 1.5 \\
\hline & $\max$ & 4.8 & 3.1 & 4.4 & 4.6 & 2.2 \\
\hline & $\min$ & 3.1 & 1.4 & 1.5 & 1.5 & 1.2 \\
\hline \multirow[t]{3}{*}{$\mathrm{OC} / \mathrm{EC}$} & mean & 2.8 & 6.1 & 4.6 & 5.3 & 8.0 \\
\hline & $\max$ & 3.6 & 7.2 & 6.6 & 6.4 & 10.2 \\
\hline & $\min$ & 2.4 & 5.2 & 3.4 & 3.3 & 5.5 \\
\hline \multirow{3}{*}{$\begin{array}{l}\text { Levoglucosan } \\
\left(\mathrm{ng} \mathrm{m}^{-3}\right)\end{array}$} & mean & 702 & 692 & 385 & 569 & 405 \\
\hline & $\max$ & 885 & 963 & 635 & 807 & 470 \\
\hline & $\min$ & 574 & 379 & 173 & 236 & 339 \\
\hline \multirow[t]{3}{*}{ Levoglucosan/OC } & mean & 0.06 & 0.05 & 0.04 & 0.04 & 0.03 \\
\hline & $\max$ & 0.08 & 0.06 & 0.05 & 0.04 & 0.04 \\
\hline & $\min$ & 0.06 & 0.04 & 0.02 & 0.03 & 0.02 \\
\hline
\end{tabular}

Table 7: PM, OC, EC and levoglucosan concentrations at five sites in Lombardy. 
1

2

3

4

5

6

7

8

9

10

11

12

13

14

15

16

17

18

19

20

21

22

23

24

25

26

27

28

29

30

31

32

33

34

35

36

37

38

39

40

41

42

43

44

45

46

47

48

49

50

51

52

53

54

55

56

57

58

59

60

\section{Figure captions}

Figure 1: Instrument scheme: three way valve for column regeneration (box a) and post column addition to increase the response factor (box b)

Figure 2: Increase of $\mathrm{pH}$ and response factor pattern

Figure 3: Comparison between chromatogram for three anydrosugars obtained with two different potential cycles: the higher peaks are those obtained with waveform B.

Figure 4: Comparison between the signals obtained using waveform A and waveform B for levoglucosan in a set of real PM samples.

Figure 5: Correlation between HPAEC-PAD and GC-FID results for levoglucosan 


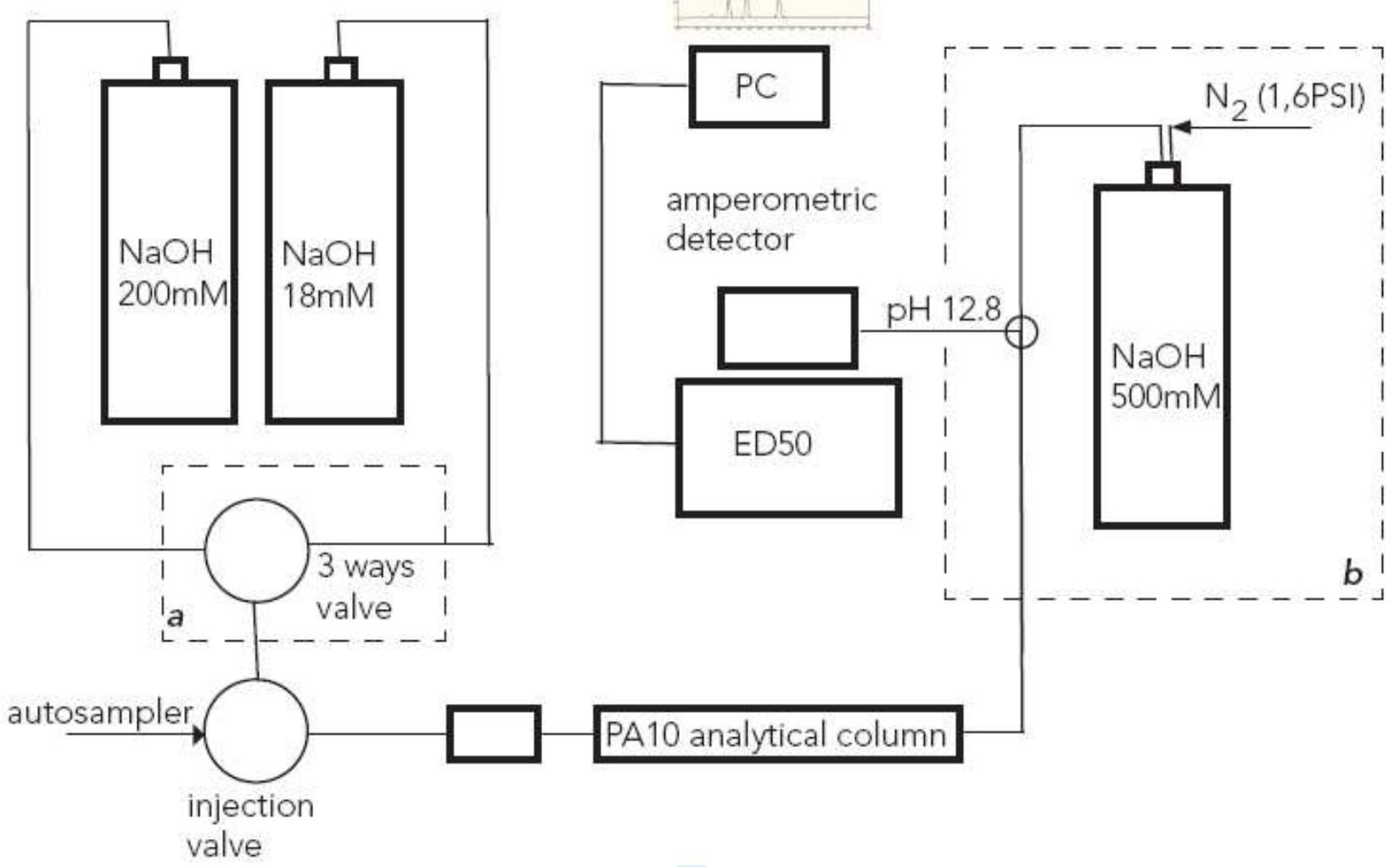

figure 1 


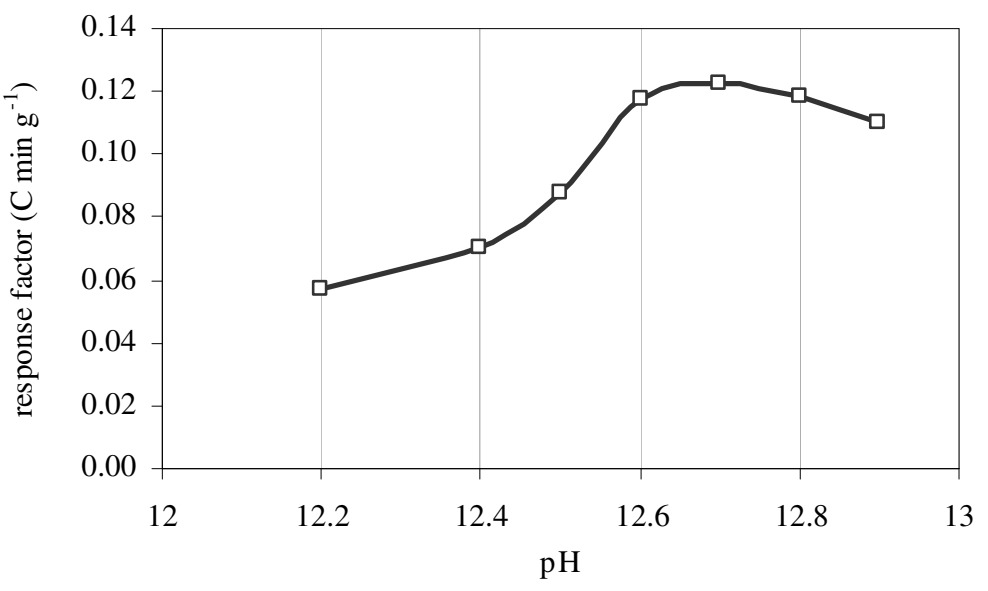

figure 2 


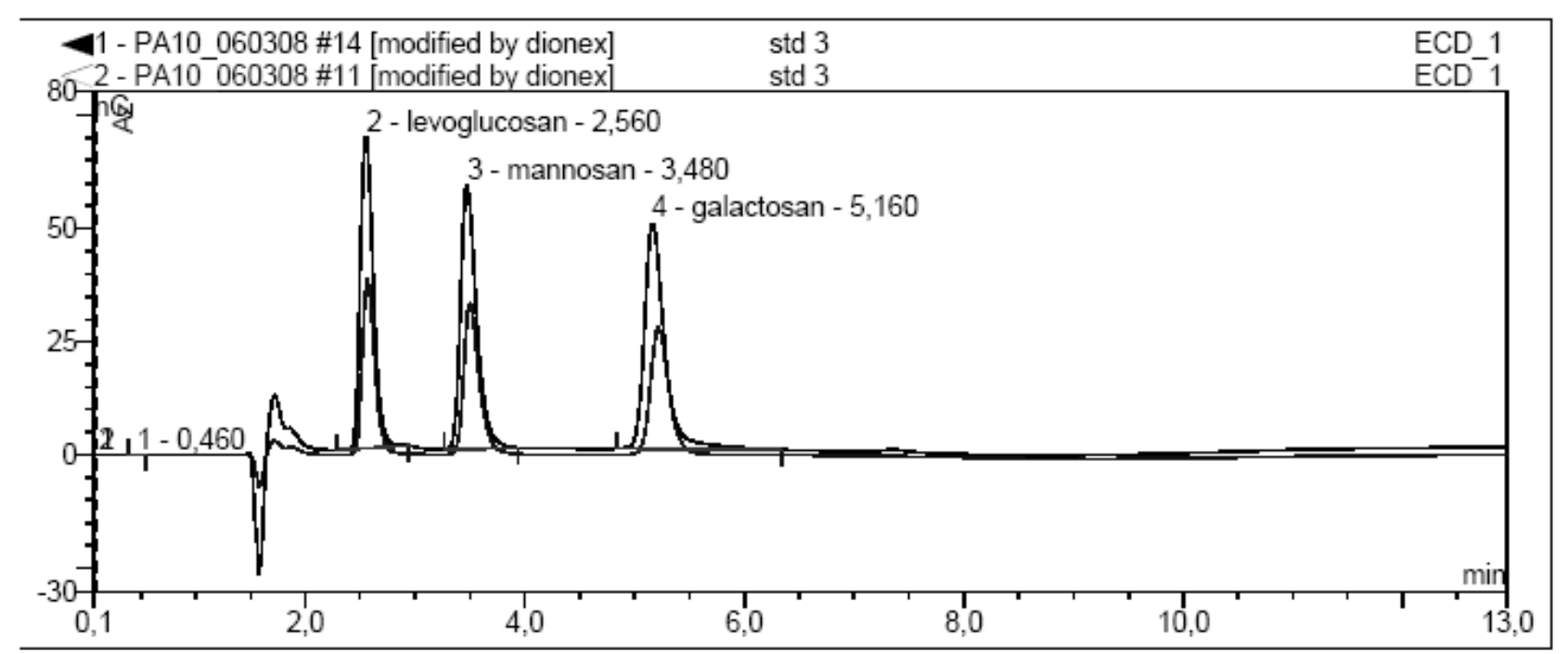

figure 3 


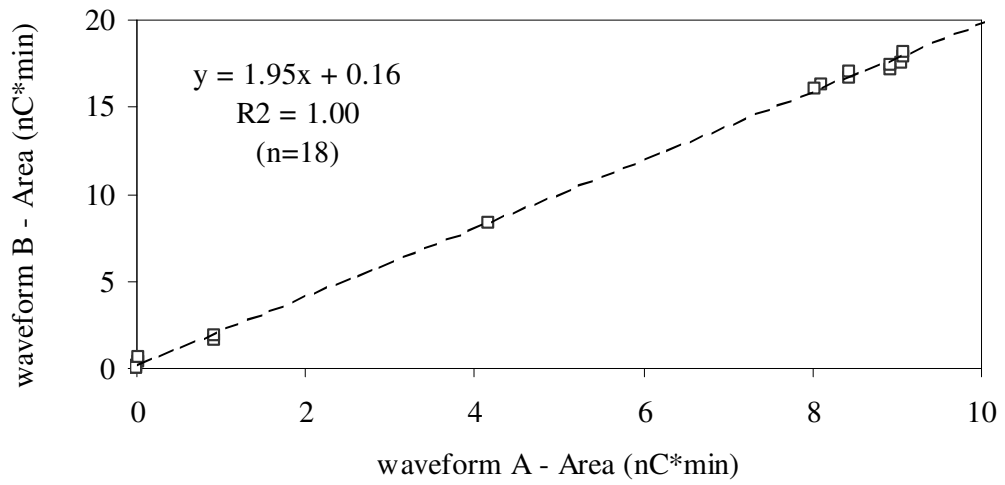

figure 4 


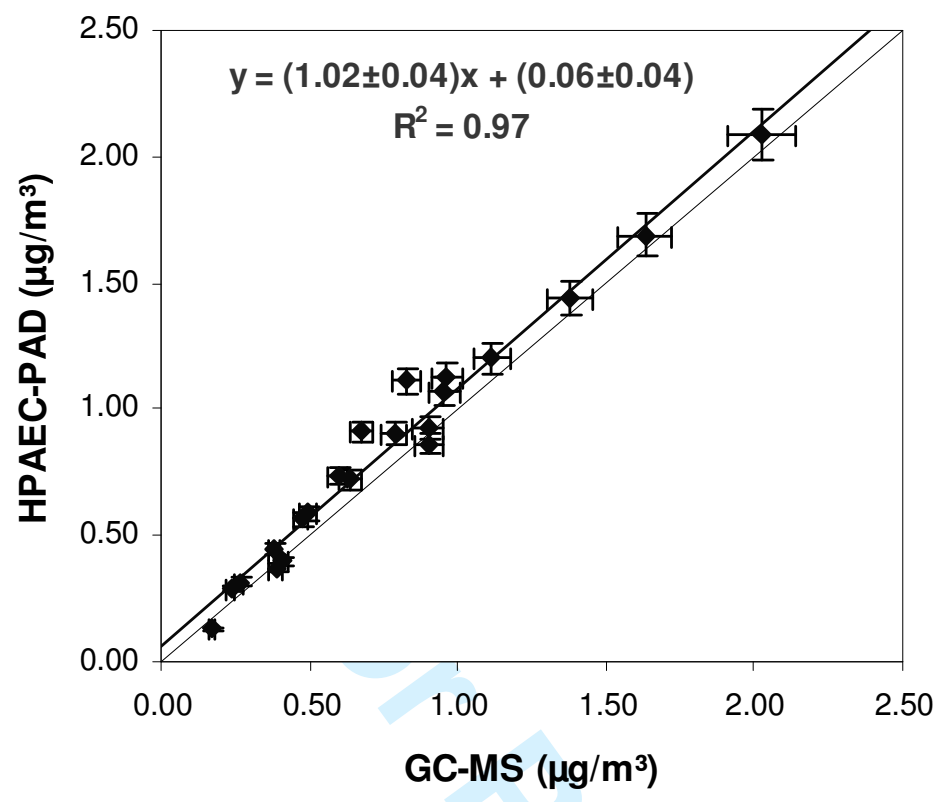

figure 5 